\title{
Contagion of Sovereign Debt in the Eurozone
}

\author{
Astrid Ayala, Szabolcs Blazsek \\ School of Business, Universidad Francisco Marroquín, Guatemala City, Guatemala \\ Email: sblazsek@ufm.edu
}

Received December 4, 2013; revised January 4, 2014; accepted January 11, 2014

Copyright (C) 2014 Astrid Ayala, Szabolcs Blazsek. This is an open access article distributed under the Creative Commons Attribution License, which permits unrestricted use, distribution, and reproduction in any medium, provided the original work is properly cited. In accordance of the Creative Commons Attribution License all Copyrights (C) 2014 are reserved for SCIRP and the owner of the intellectual property Astrid Ayala, Szabolcs Blazsek. All Copyright (C) 2014 are guarded by law and by SCIRP as a guardian.

\begin{abstract}
This study reports contagion and interdependence of quarterly debt to gross domestic product (GDP) among the member states of the Eurozone over the period 2000 Q4 to 2012 Q1. We test for contagion and interdependence in two steps. First, we define an indicator variable of increasing debt to GDP for each country during the period following the United States financial crisis, by using unit root tests incorporating structural changes and breaking trend regressions. Second, the indicator variable is included in the latent-factor panel data model to separate contagion and interdependence of debt to GDP among Eurozone member states. Results show significant and country-dependent contagion and interdependence effects of debt to GDP in the Eurozone.
\end{abstract}

\section{KEYWORDS}

\section{European Monetary Union; Sovereign Debt; Fiscal Crisis; Contagion and Interdependence; Efficient Importance Sampling}

\section{Introduction}

Several governments of the European Monetary Union (EMU) have experienced fiscal crises as a consequence of the 2008 subprime mortgage crisis of the United States (US) and the subsequent global economic and financial meltdown. This motivated a large number of studies about EMU member states' public debt during the crisis period and afterwards (e.g., [1-4]). As the crisis impacted the Eurozone, investors updated their judgments and preferences about the riskiness of sovereign bonds issued by Eurozone governments and many creditors moved from risky to safe investments, exhibiting flight to quality. In the financial markets, this process is considered as a channel of contagion (see [5-8]). In the context of credit instruments, contagion caused by updated risk judgment of investors is documented in the literature. Several studies capture revised risk assessment of investors by analyzing credit default swap prices ([8-10]). Several authors report contagion effects in international debt markets $([11,12])$. Furthermore, [13-16] also provide evidence of contagion in the context of debt instruments.

In this study, we test for contagion and interdependence of debt to gross domestic product (GDP) among the Eurozone member states over the period 2000 Q4 to
2012 Q1. We apply the econometric framework of [17] to measure contagion and interdependence of government debt in the Eurozone. We proceed in two steps.

In the first step, we employ unit root tests involving structural breaks (by $[18,19])$ and break trend regression models in order to define an indicator variable. This variable indicates if the debt to GDP time series of a Eurozone member state has had an increasing trend during some part of the period 2007 Q4 to 2012 Q1 (i.e., after the start of the US financial crisis). We also perform an extended unit root test with three structural breaks to validate the robustness of the unit root tests applied.

In the second step, we include the indicator variable in the contagion model of [17]. In this model, indicator variables capture contagion of debt to GDP. Furthermore, interdependence is driven by a dynamic latent common factor. We consider a dynamic common factor in the EMU public debt, since the operational framework (e.g., key interest rate decisions; open market operations) of the European Central Bank (ECB) influences government bond yields and, therefore, the level of debt to GDP in the Eurozone.

We extend the latent-factor specification of [17], since the latent variables representing the common factor can 
be serially correlated. We estimate the extended model by the maximum simulated likelihood method, using the efficient importance sampling (EIS) technique of [20]. Furthermore, parameter estimates are validated by residual diagnostic tests.

The remaining part of this work is organized as follows. Structural breaks of public finances in the Eurozone are estimated and indicator variables are defined in Section 2. Contagion and interdependence of debt to GDP are analyzed in Section 3. We conclude in Section 4. The EIS based maximum simulated likelihood method and computation of the common factor are presented in two appendices.

\section{Structural Breaks of Public Finances in the Eurozone}

We study quarterly government debt to GDP data for 17 member states of the EMU for the time period 2000 Q4 to 2012 Q1.(Data source: Eurostat Statistics Database of the European Commission.)We denote the debt to GDP ratio of country $i=1, \cdots, N$ in quarter $t=1, \cdots, T$ by $y_{i t}$. Table 1 presents the list of the EMU member states in 2012, shows in which year each country has adopted the euro currency, and exhibits some descriptive statistics of $y_{i t}$.

\subsection{Estimation of Break Point Dates}

We perform three alternative unit root tests for the debt to GDP time series of each country to identify the number and date(s) of the structural break(s) over the period 2000 Q4 to 2012 Q1. Each test uses a particular number of break(s) and suggests the corresponding breakpoint date(s). The best unit root test is selected according to the adjusted R-squared $\left(R_{a}^{2}\right)$ metric of the unit root test equation.

The first test applied for the $y_{i t}$ time series is the augmented Dickey-Fuller (ADF) unit root test introduced by [21]. The specification estimated includes a constant term and a linear time trend. This test does not consider structural changes in the time series. Table 2 presents the ADF test statistic, its significance and the $R_{a}^{2}$ of the ADF test equation for each country.

The second unit root test applied is by [19], which involves one structural break in the constant as well as in the linear time trend. The breakpoint date is estimated by the model. [19] extend previous unit root tests by considering a unit root with break under the null hypothesis, $H_{0}$. There are several unit root tests that consider the possibility of one structural break in a time series ([22-25]). A common feature of these tests is that they omit the possibility of a unit root process with break un-

Table 1. Descriptive statistics of government debt to GDP.

\begin{tabular}{|c|c|c|c|c|c|c|c|}
\hline Country & Start & Mean & Min & Max & SD & $\mathrm{ADF}$ & p-value \\
\hline Austria & 1999 & 0.685 & 0.602 & 0.735 & 0.034 & -1.797 & 0.382 \\
\hline Belgium & 1999 & 0.980 & 0.840 & 1.101 & 0.071 & -1.821 & 0.371 \\
\hline Cyprus & 2008 & 0.645 & 0.489 & 0.746 & 0.064 & -2.083 & 0.252 \\
\hline Estonia & 2011 & 0.052 & 0.034 & 0.072 & 0.010 & -1.157 & 0.695 \\
\hline Finland & 1999 & 0.413 & 0.299 & 0.491 & 0.046 & -1.766 & 0.398 \\
\hline France & 1999 & 0.685 & 0.566 & 0.892 & 0.094 & 0.622 & 0.990 \\
\hline Germany & 1999 & 0.682 & 0.587 & 0.830 & 0.069 & 0.443 & 0.985 \\
\hline Greece & 2001 & 1.142 & 0.973 & 1.653 & 0.182 & -0.905 & 0.778 \\
\hline Ireland & 1999 & 0.463 & 0.246 & 1.085 & 0.264 & -2.506 & 0.114 \\
\hline Italy & 1999 & 1.104 & 1.031 & 1.233 & 0.055 & -0.960 & 0.770 \\
\hline Luxembourg & 1999 & 0.096 & 0.055 & 0.209 & 0.053 & -0.223 & 0.933 \\
\hline Malta & 2008 & 0.658 & 0.549 & 0.750 & 0.049 & -1.398 & 0.585 \\
\hline Netherlands & 1999 & 0.544 & 0.453 & 0.668 & 0.061 & -0.185 & 0.933 \\
\hline Portugal & 1999 & 0.704 & 0.501 & 1.116 & 0.165 & 1.686 & 1.000 \\
\hline Slovakia & 2009 & 0.386 & 0.258 & 0.503 & 0.073 & -1.288 & 0.638 \\
\hline Slovenia & 2007 & 0.300 & 0.219 & 0.477 & 0.070 & -0.989 & 0.759 \\
\hline Spain & 1999 & 0.500 & 0.355 & 0.721 & 0.094 & -0.051 & 0.953 \\
\hline
\end{tabular}

Names of the EMU founder states are written by bold letters. Start denotes the year of euro adoption for each country. Min, Max, SD and ADF denote maximum, minimum, standard deviation and augmented Dickey-Fuller, respectively. The last column shows the p-value of the ADF test statistic. 
Table 2. Structural breaks in government debt to GDP.

\begin{tabular}{|c|c|c|c|c|c|c|c|c|c|c|c|c|c|c|}
\hline \multirow[b]{2}{*}{ Country } & \multicolumn{2}{|c|}{ ADF test [21] } & \multicolumn{5}{|c|}{ LS (2004) test [19] } & \multicolumn{7}{|c|}{ LS (2003) test [18] } \\
\hline & TS & $R_{a}^{2}$ & TS & $R_{a}^{2}$ & $\beta_{1}$ & $T_{B}$ & $\beta_{2}$ & TS & $R_{a}^{2}$ & $\beta_{1}$ & $T_{1 \mathrm{~B}}$ & $\beta_{2}$ & $T_{2 B}$ & $\beta_{3}$ \\
\hline Austria & $-3.23^{*}$ & $16 \%$ & $-5.27^{* * *}$ & $66 \%$ & -0.06 & 07Q4 & $\underline{0.78}$ & $-7.57^{* * *}$ & $61 \%$ & NA & 07Q4 & NA & 09Q2 & NA \\
\hline Belgium & -1.70 & $59 \%$ & $-6.92^{* * *}$ & $61 \%$ & -0.86 & 07Q4 & $\underline{0.89}$ & $-7.58^{* * *}$ & $55 \%$ & NA & 07Q4 & NA & 09Q3 & NA \\
\hline Cyprus & -1.60 & $2 \%$ & $-5.65^{* * *}$ & $67 \%$ & NA & 08Q4 & NA & $-8.30^{* * *}$ & $69 \%$ & 0.95 & 04Q2 & -1.34 & 08Q4 & $\underline{1.11}$ \\
\hline Estonia & -1.48 & $8 \%$ & $-8.00^{* * *}$ & $66 \%$ & NA & 07Q3 & NA & $-8.28^{* * *}$ & $67 \%$ & -0.05 & 07Q3 & 0.39 & 10Q1 & -0.13 \\
\hline Finland & -1.39 & $3 \%$ & $-5.63^{* * *}$ & $63 \%$ & -0.29 & 08Q3 & $\underline{1.24}$ & $-7.68^{* * *}$ & $61 \%$ & NA & 04Q4 & NA & 08Q3 & NA \\
\hline France & -2.05 & $26 \%$ & $-7.54^{* * *}$ & $72 \%$ & 0.33 & 08Q4 & $\underline{1.33}$ & $-9.01^{* * *}$ & $69 \%$ & NA & 08Q4 & NA & 10Q2 & NA \\
\hline Germany & -1.54 & $3 \%$ & $-7.70^{* * *}$ & $64 \%$ & NA & 10Q4 & NA & $-8.36^{* * *}$ & $70 \%$ & 0.54 & 06Q3 & -0.47 & 08Q3 & $\underline{1.21}$ \\
\hline Greece & -2.19 & $6 \%$ & $-6.74^{* * *}$ & $62 \%$ & 0.28 & 08Q3 & $\underline{3.15}$ & $-7.55^{* * *}$ & $60 \%$ & NA & 05Q4 & NA & 08Q3 & NA \\
\hline Ireland & -0.03 & $33 \%$ & $-7.90^{* * *}$ & $69 \%$ & -0.40 & 07Q4 & $\underline{5.37}$ & $-8.38^{* * *}$ & $67 \%$ & NA & 07Q4 & NA & 11Q1 & NA \\
\hline Italy & -1.48 & $50 \%$ & $-4.91^{* *}$ & $64 \%$ & -0.13 & 08Q3 & $\underline{1.06}$ & $-7.64^{* * *}$ & $61 \%$ & NA & $08 \mathrm{Q} 3$ & NA & 09Q3 & NA \\
\hline Luxembourg & -1.45 & $6 \%$ & $-4.66^{* *}$ & $66 \%$ & 0.03 & 08Q3 & $\underline{0.66}$ & $-7.21^{* * *}$ & $56 \%$ & NA & 08Q3 & NA & 10Q1 & NA \\
\hline Malta & -1.55 & $1 \%$ & $-5.06^{* *}$ & $70 \%$ & NA & 05Q1 & NA & $-6.98^{* * *}$ & $75 \%$ & 1.04 & 05Q1 & -0.80 & 08Q4 & $\underline{0.71}$ \\
\hline Netherlands & -1.32 & $5 \%$ & $-4.97^{* *}$ & $87 \%$ & -0.20 & 08Q3 & $\underline{0.81}$ & $-6.90^{* * *}$ & $73 \%$ & NA & 08Q3 & NA & 09Q1 & NA \\
\hline Portugal & 0.24 & $10 \%$ & $-6.07^{* * *}$ & $68 \%$ & NA & 08Q3 & NA & $-8.13^{* * *}$ & $69 \%$ & 0.82 & 06Q2 & -0.18 & 08Q3 & $\underline{3.12}$ \\
\hline Slovakia & 0.52 & $16 \%$ & $-6.60^{* * *}$ & $67 \%$ & -0.84 & 08Q3 & $\underline{1.35}$ & $-7.84^{* * *}$ & $63 \%$ & NA & 02Q2 & NA & 08Q3 & NA \\
\hline Slovenia & -0.39 & $4 \%$ & $-5.32^{* * *}$ & $67 \%$ & -0.12 & 08Q4 & $\underline{1.84}$ & $-7.89^{* * *}$ & $63 \%$ & NA & 08Q4 & NA & 11Q1 & NA \\
\hline Spain & 0.32 & $67 \%$ & $-6.83^{* * *}$ & $70 \%$ & -0.79 & 08Q1 & $\underline{2.38}$ & $-8.75^{* * *}$ & $69 \%$ & NA & 08Q1 & NA & 11Q2 & NA \\
\hline
\end{tabular}

Augmented Dickey-Fuller (ADF [21]). Lee and Strazicich (LS [18,19]). Test statistic (TS). Adjusted R-squared $\left(R_{a}^{2}\right)$. Not available (NA). $T_{B}$ and $T_{j B}$ denote the quarter of the structural break, where the first two digits show the year and the last digit indicates the quarter of year. The ADF and LS tests are with constant(s) and with linear time trend(s). ${ }^{*},{ }^{* *}$ and ${ }^{* * *}$ denote significance at the 10,5 and 1 percent levels, respectively. $R_{a}^{2}$ corresponds to the test equation of each unit root test. $R_{a}^{2}$ and break dates with bold font indicate the best unit root test for each country. The $\beta_{j}$ values are parameter estimates of breaking trend regressions. The $\beta_{j}$ coefficients underlined indicate that the debt to GDP has an increasing trend from 2007 Q4.

der the null hypothesis. Therefore, spurious rejections of $H_{0}$ may occur. In the [19] test, the following test equation is estimated:

$$
\Delta y_{i t}=\delta_{i}^{\prime} \Delta Z_{i t}+\phi_{i} \tilde{S}_{i t-1}+\sum_{j=1}^{k} c_{i j} \Delta \tilde{S}_{i t-j}+e_{i t},
$$

where $\Delta$ denotes the first difference of the corresponding time series, $\tilde{S}_{i t}=y_{i t}-\tilde{\Psi}_{x}-Z_{i t} \tilde{\delta}_{i}$ and $\tilde{\Psi}_{x}=y_{i 1}-Z_{i 1} \tilde{\delta}_{i}$. $\tilde{\delta}_{i}$ denotes the vector of coefficients estimated by a regression of $\Delta y_{i t}$ on $\Delta Z_{i t}$. The $\Delta \tilde{S}_{i t-j}$ terms are included to correct for serial correlation. See [19] for the selection of the number of augmentation terms, $k$.

$$
Z_{i t}=\left[t, B_{i t}, D T_{i t}\right]^{\prime}
$$

and

$$
\Delta Z_{i t}=\left[1, \Delta B_{i t}, \Delta D T_{i t}\right]^{\prime}
$$

where

$$
\begin{gathered}
B_{i t}= \begin{cases}1 & \text { if } t \geq T_{B i}+1 \\
0 & \text { otherwise }\end{cases} \\
D T_{i t}= \begin{cases}t-T_{B i} & \text { if } t \geq T_{B i}+1 \\
0 & \text { otherwise }\end{cases}
\end{gathered}
$$

and $T_{B i}$ denotes the time of the structural break for country $i$. Table 2 presents the [19] test statistic, its significance and the $R_{a}^{2}$ of the [19] test equation for each country.

The third unit root test applied is the [18] test, which involves two structural breaks in the constant as well as in the linear time trend. The two breakpoint dates are estimated by the model. [18] extended previous models by including two structural breaks in $H_{0}$. Unit root tests with a single structural break do not consider the possibility that the variable has several structural breaks. This fact motivated [26] to include two structural breaks in their unit root test. These authors do not consider structural breaks under the null hypothesis, which may yield spurious rejection of $H_{0}$. The test equation of [18] is Equation (1) with

$$
Z_{i t}=\left[t, B_{1 i t}, B_{2 i t}, D T_{1 i t}, D T_{2 i t}\right]^{\prime}
$$

and

$$
\Delta Z_{i t}=\left[1, \Delta B_{1 i t}, \Delta B_{2 i t}, \Delta D T_{1 i t}, \Delta D T_{2 i t}\right]^{\prime},
$$

where 


$$
\begin{gathered}
B_{j i t}= \begin{cases}1 & \text { if } t \geq T_{B j i}+1 \\
0 & \text { otherwise }\end{cases} \\
D T_{j i t}= \begin{cases}t-T_{B j i} & \text { if } t \geq T_{B j i}+1 \\
0 & \text { otherwise }\end{cases}
\end{gathered}
$$

and $T_{B j i}$ is the time of the structural break $j=1,2$ for country $i$. Table 2 presents the [18] test statistic, its significance and the $R_{a}^{2}$ of the [18] test equation for each country.

For each country, we use the results of the unit root test with the highest $R_{a}^{2}$ value. Table 2 shows that the unit root test equation with the highest explanatory power is always a unit root test involving one or two structural breaks. Furthermore, Table 2 shows that the unit root null hypothesis is always rejected for the best model, i.e. a breaking trend process is suggested for all countries.

\subsection{Robustness Analysis of Structural Breaks}

The unit root test results reported in Table 2 show that, in several cases, the unit root test with two structural breaks has the highest $R_{a}^{2}$ value. However, unit root tests with more than two structural breaks may explain better the evolution of debt to GDP. Therefore, we perform a unit root test with three structural breaks for the countries where the [18] model has the highest $R_{a}^{2}$ metric. In this test, we use the $T_{1 B}$ and $T_{2 B}$ dates estimated by the [18] model, while $T_{3 B}$ is determined endogenously using the methodology of $[18,19]$. Conditioning on two previously estimated breaks, reduces the computation time substantially. This approach is similar to the idea of [27], who test for $l$ versus $l+1$ breaks conditioning on the locations of $l$ breaks and the additional breakpoint is determined endogenously; see also $[28,29]$. The test results, presented in Table 3 , show that the $R_{a}^{2}$ model selection metric is always lower than that of the [18] model, i.e. two breakpoints are preferred to

Table 3. Robustness analysis of unit root tests.

\begin{tabular}{cccccc}
\hline Country & TS & $R_{a}^{2}$ & $T_{1 в}$ & $T_{2 в}$ & $T_{3 в}$ \\
\hline Cyprus & $-8.81^{* *}$ & $68 \%$ & $04 \mathrm{Q} 2$ & $08 \mathrm{Q} 4$ & $09 \mathrm{Q} 2$ \\
Estonia & $-8.73^{* * *}$ & $65 \%$ & $02 \mathrm{Q} 1$ & $07 \mathrm{Q} 3$ & $10 \mathrm{Q} 1$ \\
Germany & $-9.17^{* * *}$ & $68 \%$ & $06 \mathrm{Q} 3$ & $08 \mathrm{Q} 3$ & $10 \mathrm{Q} 4$ \\
Malta & $-7.43^{* * *}$ & $72 \%$ & $02 \mathrm{Q} 4$ & $05 \mathrm{Q} 1$ & $08 \mathrm{Q} 4$ \\
Netherlands & $-7.31^{* * *}$ & $71 \%$ & $05 \mathrm{Q} 2$ & $08 \mathrm{Q} 3$ & $09 \mathrm{Q} 1$ \\
Portugal & $-8.72^{* * *}$ & $67 \%$ & $06 \mathrm{Q} 2$ & $08 \mathrm{Q} 3$ & $11 \mathrm{Q} 1$ \\
\hline
\end{tabular}

Test statistic (TS). Adjusted R-squared $\left(R_{a}^{2}\right) . T_{j B}$ denotes the quarter of the structural break, where the first two digits show the year and the last digit indicates the quarter of year. ${ }^{* *}$ and ${ }^{* * *}$ denote significance at the 5 and 1 percent levels, respectively. three breakpoints according to the $R_{a}^{2}$. This finding supports the use of the [18] unit root test.

\subsection{Increasing Debt to GDP during the Crisis}

In this section, we define an indicator variable, $I_{i t}$ that represents if debt to GDP has an increasing tendency during some part of the period 2007 Q4 to 2012 Q1 (i.e., from the start of the US financial crisis). We use the results for the highest $R_{a}^{2}$ unit root test for each country. The best unit root test estimates the date(s) of structural break(s) in debt to GDP and suggests a breaking trend process for the evolution of debt to GDP for all countries (see Table 2). We estimate the tendency of $y_{i t}$ by two alternative breaking trend regression models. When the [19] test provides the breakpoint dates, we estimate the following regression model:

$$
y_{i t}=\mu_{1 i} D U_{1 i t}+\mu_{2 i} D U_{2 i t}+\beta_{1 i} T I M E_{1 i t}+\beta_{2 i} T I M E_{2 i t}+u_{i t} \text {, }
$$

where $u_{i t}$ is a possibly serially correlated error term.

$$
D U_{1 i t}=1 \text { if } t \leq T_{B i}
$$

and zero otherwise,

$$
D U_{2 i t}=1 \text { if } t>T_{B i}
$$

and zero otherwise,

$$
T I M E_{1 i t}=t \text { if } t \leq T_{B i}
$$

and zero otherwise, and

$$
T I M E_{2 i t}=t-T_{B i} \text { if } t>T_{B i}
$$

and zero otherwise. When the [18] test provides the breakpoint dates, we estimate the following regression model:

$$
\begin{aligned}
y_{i t}= & \mu_{1 i} D U_{1 i t}+\mu_{2 i} D U_{2 i t}+\mu_{3 i} D U_{3 i t}+\beta_{1 i} T I M E_{1 i t} \\
& +\beta_{2 i} T M E_{2 i t}+\beta_{3 i} T I M E_{3 i t}+u_{i t}
\end{aligned},
$$

where $u_{i t}$ is a possibly serially correlated error term.

$$
D U_{1 i t}=1 \text { if } t \leq T_{B 1 i}
$$

and zero otherwise,

$$
D U_{2 i t}=1 \text { if } T_{B 1 i}<t \leq T_{B 2 i}
$$

and zero otherwise,

$$
D U_{3 i t}=1 \text { if } t>T_{B 2 i}
$$

and zero otherwise,

$$
T I M E_{1 i t}=t \text { if } t \leq T_{B 1 i}
$$

and zero otherwise,

$$
T I M E_{2 i t}=t-T_{B 1 i} \text { if } T_{B 1 i}<t \leq T_{B 2 i}
$$

and zero otherwise, and

$$
T I M E_{3 i t}=t-T_{B 2 i} \text { if } t>T_{B 2 i}
$$

and zero otherwise. 
Table 2 shows the $\beta_{j i}$ parameter estimates for the breaking trend regressions. The $\beta_{j i}$ coefficients underlined indicate that the debt to GDP has an increasing trend during some part of the period 2007 Q4 to 2012 Q1. The estimated breakpoint dates around the $\beta_{j i}$ underlined indicate the sub-period when the debt to GDP increases for country $i$. The indicator variable, $I_{i t}$ for an EMU member country $i$ in period $t$ takes the value one when the $\beta_{j i}$ underlined is significantly positive. $I_{i t}$ will be used in Section 3 to construct a measure of contagion of public debt within the Eurozone.

\section{Contagion of Public Debt in the Eurozone}

\subsection{Contagion Model}

We apply the econometric model of contagion of [17] to measure contagion of public finances in the Eurozone. These authors distinguish contagion from interdependence and identify the parameters measuring contagion effects. The ADF results of debt to GDP presented in Table 1 evidence that the unit root null hypothesis cannot be rejected for any country in the Eurozone. This motivates us to formulate the econometric model of contagion for first differences, $\Delta y_{i t}=y_{i t}-y_{i t-1}$, as follows:

$$
\begin{gathered}
\Delta y_{i t}=\phi_{1 i} y_{i t-1}+\phi_{2 i} y_{i t-1}^{2}+\psi_{i} D_{i t}\left(\frac{\sum_{j=1, j \neq i}^{N} I_{j t}}{N-1}\right)+u_{i t} \\
u_{i t}=\gamma_{i} D_{i t} l_{t}^{*}+\sigma_{i} \varepsilon_{i t}, \quad \varepsilon_{i t} \sim N(0,1) \text { i.i.d } \\
l_{t}^{*}=\mu^{*} l_{t-1}^{*}+\eta_{t}, \quad \eta_{t} \sim N(0,1) \text { i.i.d. }
\end{gathered}
$$

For $i=1, \cdots, N$ and $t=1, \cdots, T$. The model includes a dummy variable, $D_{i t}$ defined as follows: $D_{i t}=1$ if country $i$ is EMU member in period $t$ and zero otherwise (see Table 1). Moreover, the model also includes the indicator variable, $I_{i t}$, defined in Section 2. The definition of the indicator variable in a first step (i.e., Section 2) is similar to the approach of [17]. They also choose the threshold parameter to define the crisis indicator dummy in a first step. $l_{t}^{*}$ is a first-order autoregressive (AR) latent factor with dynamic parameter $\left|\mu^{*}\right|<1$. In Equation (6), the constant term in the latent process is restricted to zero and the variance of $\eta_{t}$ is restricted to one due to identification reasons.

In this model, interdependence is captured by $\rho=\operatorname{corr}\left(u_{i t}, u_{j t}\right)$ and contagion effects are measured by $\psi_{i}$ (see [17]). We multiply by the EMU-membership dummy, $D_{i t}$ both the contagion and the latent factor terms of the model, since interdependence and contagion is measured only among the EMU member states. The model includes the following parameters. Initial conditions of the dynamic model, $y_{i 0} \cdot \phi_{1 i}$ and $\phi_{2 i}$ measure the dynamic effects of $y_{i t-1}$ and $y_{i t-1}^{2}$, respectively. The quadratic term is included to capture possible non-linear dynamics. We find the $\phi_{2 i}$ parameter statistically significant for most countries; see Table 4. $\psi_{i}$ measures the impact of the average of other EMU states' indicator variables, i.e., contagion of public debt. $\gamma_{i}$ captures the impact of the latent factor, $l_{t}^{*}$. $\sigma_{i}$ measures the standard deviation of the country-specific error term, $\varepsilon_{i t}$.We assume that the country-specific standard deviation is constant. Motivated by the discussion in [30], we also estimated the model with a GARCH $(1,1)$ error term ([31]). However, the results did not show significant GARCH dynamic in the error term.

This model is an extension of the latent-factor specification of [17], since the common factor, $l_{t}^{*}$ is serially correlated. For this reason, we use a simulation-based estimation method designed for the estimation of models with dynamic latent variables. The parameters of the model, i.e.,

$$
\theta=\left(y_{i 0}, \phi_{1 i}, \phi_{2 i}, \psi_{i}, \gamma_{i}, \sigma_{i}, \mu^{*}\right)
$$

with $i=1, \cdots, N$, are estimated by the maximum simulated likelihood method (see [32]), using the EIS technique of [20]. The EIS technique has been applied successfully for the precise evaluation of likelihood functions involving high-dimensional integrals (e.g., [33-35]). We present the computation of the likelihood function in Appendix A.

Table 4 presents the parameter estimates of the contagion model. The last column of this table shows the relative importance of the contagion component of debt to GDP. For each country, the table presents the average of

$$
\psi_{i} D_{i t}\left(\frac{\sum_{j=1, j \neq i}^{N} I_{j t}}{N-1}\right) / y_{i t},
$$

computed over the period 2007 Q4 to 2012 Q1 (i.e., from the start of the US financial crisis). Results show that the average contribution of debt contagion of other EMU member states is the highest for Luxembourg (19\%), followed by, Ireland (10\%), the Netherlands (7\%), Slovenia (7\%), Greece (6\%), Spain (6\%) and Slovakia (5\%).

Table 5 presents the estimates of interdependence, $\rho$, among the Eurozone states' debt to GDP. Results suggest significant and, in most cases, positive interdependence of debt to GDP within the EMU.

\subsection{Residual Diagnostic Tests}

The correct specification of the error term, $\varepsilon_{i t}$ is analyzed by residual diagnostic tests. Residuals are computed as follows:

$$
\begin{aligned}
\hat{\varepsilon}_{i t}=\hat{\sigma}_{i}^{-1} & {\left[\Delta y_{i t}-\hat{\phi}_{1 i} y_{i t-1}-\hat{\phi}_{2 i} y_{i t-1}^{2}\right.} \\
& \left.-\hat{\psi}_{i} D_{i t}\left(\frac{\sum_{j=1, j \neq i}^{N} I_{j t}}{N-1}\right)-\hat{\gamma}_{i} D_{i t} \hat{l}_{t}^{*}\right] .
\end{aligned}
$$


Table 4. Parameter estimates of the contagion model.

\begin{tabular}{|c|c|c|c|c|c|c|c|}
\hline Country & $y_{i 0}$ & $\phi_{1 i}$ & $\phi_{2 i}$ & $\psi_{i}$ & $\gamma_{i}$ & $\sigma_{i}$ & Contagion (\%) \\
\hline Austria & $0.649^{* * *}$ & $0.387^{* * *}$ & $-0.566^{* * *}$ & $0.012^{* *}$ & $0.023^{* * *}$ & $0.013^{*}$ & $1 \%$ \\
\hline Belgium & $1.098^{* * *}$ & $0.127^{* * * *}$ & $-0.132^{* * *}$ & $0.010^{*}$ & $0.021^{* * *}$ & $0.016^{* *}$ & $1 \%$ \\
\hline Cyprus & $0.581^{* * *}$ & $0.206^{* * *}$ & $-0.310^{* * *}$ & 0.006 & $0.056^{* * *}$ & $0.022^{* *}$ & $1 \%$ \\
\hline Estonia & $0.051^{* *}$ & 0.047 & -0.758 & -0.002 & 0.004 & $0.003^{*}$ & $0 \%$ \\
\hline Finland & $0.446^{* * *}$ & $0.060^{* * *}$ & $-0.175^{* * *}$ & $0.019^{* * *}$ & $-0.007^{* *}$ & $0.020^{* *}$ & $4 \%$ \\
\hline France & $0.569^{* * *}$ & $0.072^{* * *}$ & $-0.106^{* * *}$ & $0.027^{* * *}$ & $0.005^{* * *}$ & $0.009^{*}$ & $3 \%$ \\
\hline Germany & $0.596^{* * *}$ & $0.090^{* * *}$ & $-0.135^{* * *}$ & $0.021^{* * *}$ & 0.003 & $0.012^{*}$ & $2 \%$ \\
\hline Greece & $1.035^{* * *}$ & $0.162^{* * *}$ & $-0.158^{* * *}$ & $0.095^{* * *}$ & -0.005 & $0.050^{* * *}$ & $6 \%$ \\
\hline Ireland & $0.379^{* * *}$ & 0.012 & $-0.065^{* * *}$ & $0.087^{* * *}$ & $0.007^{* * *}$ & $0.021^{* *}$ & $10 \%$ \\
\hline Italy & $1.088^{* * *}$ & $0.216^{* * *}$ & $-0.201^{* * *}$ & $0.033^{* * *}$ & $0.016^{* * *}$ & $0.011^{*}$ & $2 \%$ \\
\hline Luxembourg & $0.063^{* *}$ & $0.067^{* * *}$ & $-1.283^{* * *}$ & $0.035^{* * *}$ & 0.000 & $0.010^{*}$ & $19 \%$ \\
\hline Malta & $0.536^{* * *}$ & $0.115^{* * *}$ & $-0.170^{* * *}$ & $0.009^{*}$ & $0.013^{* * * *}$ & $0.013^{*}$ & $1 \%$ \\
\hline Netherlands & $0.553^{* * *}$ & $0.265^{* * *}$ & $-0.527^{* * *}$ & $0.051^{* * *}$ & $0.007^{* *}$ & $0.015^{* *}$ & $7 \%$ \\
\hline Portugal & $0.498^{* * *}$ & $0.023^{*}$ & -0.023 & $0.028^{* * *}$ & 0.000 & $0.019^{* *}$ & $3 \%$ \\
\hline Slovakia & $0.513^{* * *}$ & $-0.021^{*}$ & 0.004 & $0.022^{* * *}$ & $0.010^{* * *}$ & $0.013^{* *}$ & $5 \%$ \\
\hline Slovenia & $0.263^{* * *}$ & $0.077^{* * *}$ & $-0.292^{* * *}$ & $0.031^{* * *}$ & $0.013^{* * *}$ & $0.015^{* *}$ & $7 \%$ \\
\hline Spain & $0.606^{* * * *}$ & -0.005 & $-0.025^{* * *}$ & $0.037^{* * *}$ & 0.003 & $0.007^{*}$ & $6 \%$ \\
\hline
\end{tabular}

*** and ${ }^{* * *}$ denote significance at the 10,5 and 1 percent levels, respectively.

Table 5. Interdependence of debt to GDP among the EMU states.

\begin{tabular}{|c|c|c|c|c|c|c|c|c|c|c|c|c|c|c|c|c|c|}
\hline$\rho$ & AUS & BEL & CYP & EST & FIN & FRA & GER & GRE & IRE & ITA & LUX & MAL & NED & POR & SVK & SLO & SPA \\
\hline AUS & 1.00 & & & & & & & & & & & & & & & & \\
\hline BEL & 0.64 & 1.00 & & & & & & & & & & & & & & & \\
\hline CYP & 0.78 & 0.76 & 1.00 & & & & & & & & & & & & & & \\
\hline EST & 0.20 & 0.19 & 0.23 & 1.00 & & & & & & & & & & & & & \\
\hline FIN & -0.30 & -0.29 & -0.36 & -0.09 & 1.00 & & & & & & & & & & & & \\
\hline FRA & 0.26 & 0.25 & 0.30 & 0.08 & -0.12 & 1.00 & & & & & & & & & & & \\
\hline GER & 0.13 & 0.13 & 0.15 & 0.04 & -0.06 & 0.05 & 1.00 & & & & & & & & & & \\
\hline GRE & -0.23 & -0.23 & -0.28 & -0.07 & 0.11 & -0.09 & -0.05 & 1.00 & & & & & & & & & \\
\hline IRE & 0.32 & 0.31 & 0.38 & 0.10 & -0.15 & 0.12 & 0.06 & -0.11 & 1.00 & & & & & & & & \\
\hline ITA & 0.58 & 0.56 & 0.68 & 0.17 & -0.26 & 0.22 & 0.11 & -0.20 & 0.28 & 1.00 & & & & & & & \\
\hline LUX & 0.01 & 0.01 & 0.01 & 0.00 & 0.00 & 0.00 & 0.00 & 0.00 & 0.00 & 0.01 & 1.00 & & & & & & \\
\hline MAL & 0.50 & 0.48 & 0.59 & 0.15 & -0.23 & 0.19 & 0.10 & -0.18 & 0.24 & 0.43 & 0.01 & 1.00 & & & & & \\
\hline NED & 0.31 & 0.30 & 0.36 & 0.09 & -0.14 & 0.12 & 0.06 & -0.11 & 0.15 & 0.27 & 0.00 & 0.23 & 1.00 & & & & \\
\hline POR & 0.00 & 0.00 & 0.00 & 0.00 & 0.00 & 0.00 & 0.00 & 0.00 & 0.00 & 0.00 & 0.00 & 0.00 & 0.00 & 1.00 & & & \\
\hline SVK & 0.44 & 0.43 & 0.52 & 0.13 & -0.20 & 0.17 & 0.09 & -0.15 & 0.21 & 0.38 & 0.00 & 0.33 & 0.20 & 0.00 & 1.00 & & \\
\hline SLO & 0.50 & 0.48 & 0.58 & 0.15 & -0.23 & 0.19 & 0.10 & -0.17 & 0.24 & 0.43 & 0.01 & 0.37 & 0.23 & 0.00 & 0.33 & 1.00 & \\
\hline SPA & 0.13 & 0.12 & 0.15 & 0.04 & -0.06 & 0.05 & 0.03 & -.04 & 0.06 & 0.11 & 0.00 & 0.10 & 0.06 & 0.00 & 0.08 & 0.10 & 1.00 \\
\hline
\end{tabular}

Interdependence is defined as $\rho=\operatorname{corr}\left(u_{i t}, u_{j t}\right)$. Correlation coefficients significant at the 5 percent level are presented by bold numbers. Austria (AUS); Belgium (BEL); Cyprus (CYP); Estonia (EST); Finland (FIN); France (FRA); Germany (GER); Greece (GRE); Ireland (IRE); Italy (ITA); Luxembourg (LUX); Malta (MAL); Netherlands (NED); Portugal (POR); Slovakia (SVK); Slovenia (SLO); Spain (SPA). 
We present the estimation of the latent factor, $\hat{l}_{t}^{*}$ in Appendix B. Table 6 shows the results of two residual diagnostic tests for each country. First, the $\mathrm{Z}$ test is performed with the following null hypothesis:

$(1 / T) \sum_{t=1}^{T} \hat{\varepsilon}_{i t}=0$. Second, the [36] test is performed with the following null hypothesis: $\left\{\hat{\varepsilon}_{i 1}, \cdots, \hat{\varepsilon}_{i T}\right\}$ are not serially correlated. For both tests, p-values presented in Table 6 suggest that the null hypotheses are never rejected at the 10 percent level of significance. These results support the specification of the $\varepsilon_{i t}$ error term in the contagion model and the consistency of the EISbased maximum simulated likelihood method.

\section{Conclusion}

In this study, we report contagion and interdependence of debt to GDP among the member states of the Eurozone over the period 2000 Q4 to 2012 Q1. We apply the framework of [17] to measure contagion and interdependence in two steps. First, we estimate the breakpoint dates in debt to GDP by using several unit root tests. For all countries, the unit root null hypotheses are rejected, i.e., a breaking trend process is suggested. We perform an extended unit root test with three structural breaks to validate the number of structural breaks estimated. We define an indicator variable which takes the value one if a Eurozone government has had an increasing tendency in debt to GDP during some parts of the period 2007 Q4 to 2012 Q1 or zero otherwise. Second, the indicator variable is included in the contagion model of [17], where contagion and interdependence components of debt to GDP are estimated. Contagion is driven by the mean of the indicator variables of other Eurozone governments. Interdependence is driven by a dynamic common factor, extending the latent-factor specification of [17]. We estimate the contagion model by the maximum simulated likelihood method, using the EIS technique of [20]. Furthermore, we perform residual diagnostic tests to validate the EIS parameter estimates. Results show significant and country-dependent contagion effects and interdependence of debt to GDP within the Eurozone.

\section{Acknowledgements}

Previous versions of this work were presented at the Macro-Finance Workshop, Universidad de Navarra, Pamplona, November 2011; MKE Annual Conference, Budapest, December 2011. The authors thank Gábor Körösi for helpful discussions and comments. The authors also thank the research financing of the School of Business of

Table 6. Residual diagnostics for the contagion model.

\begin{tabular}{|c|c|c|c|c|c|c|}
\hline Country & Mean & SD & Z & Z p-value & LB (16) & LB p-value \\
\hline Austria & -0.034 & 1.087 & -0.031 & 0.975 & 5.650 & 0.227 \\
\hline Belgium & -0.097 & 1.001 & -0.096 & 0.923 & 5.304 & 0.258 \\
\hline Cyprus & -0.045 & 1.095 & -0.042 & 0.967 & 5.575 & 0.233 \\
\hline Estonia & 0.069 & 1.046 & 0.066 & 0.948 & 5.237 & 0.264 \\
\hline Finland & 0.024 & 1.081 & 0.023 & 0.982 & 5.436 & 0.245 \\
\hline France & -0.049 & 1.180 & -0.041 & 0.967 & 4.580 & 0.333 \\
\hline Germany & -0.019 & 1.040 & -0.018 & 0.985 & 1.083 & 0.897 \\
\hline Greece & 0.003 & 1.013 & 0.003 & 0.998 & 0.767 & 0.943 \\
\hline Ireland & -0.015 & 1.073 & -0.014 & 0.988 & 6.561 & 0.161 \\
\hline Italy & -0.015 & 1.072 & -0.014 & 0.989 & 6.253 & 0.181 \\
\hline Luxembourg & 0.017 & 1.011 & 0.017 & 0.986 & 3.086 & 0.544 \\
\hline Malta & -0.017 & 1.104 & -0.015 & 0.988 & 4.569 & 0.334 \\
\hline Netherlands & -0.036 & 1.132 & -0.032 & 0.975 & 2.578 & 0.631 \\
\hline Portugal & 0.001 & 1.011 & 0.001 & 0.999 & 5.003 & 0.287 \\
\hline Slovakia & -0.011 & 1.084 & -0.010 & 0.992 & 7.107 & 0.130 \\
\hline Slovenia & -0.074 & 1.075 & -0.069 & 0.945 & 0.720 & 0.949 \\
\hline Spain & -0.032 & 1.076 & -0.030 & 0.976 & 5.379 & 0.251 \\
\hline
\end{tabular}

Mean and SD present the mean and standard deviation, respectively, of $\left\{\hat{\varepsilon}_{i 1}, \cdots, \hat{\varepsilon}_{i T}\right\} \cdot Z=$ Mean/SD . Null hypothesis of the Z test: $(1 / T) \sum_{t=1}^{T} \hat{\varepsilon}_{i t}=0$. Null hypothesis of the Ljung and Box (LB 1978) test: $\left\{\hat{\varepsilon}_{i 1}, \cdots, \hat{\varepsilon}_{i T}\right\}$ are not serially correlated. LB (16) is computed for 16th-order serial correlation. 
Universidad Francisco Marroquín.

\section{REFERENCES}

[1] M. Dabrowski, “The Global Financial Crisis: Lessons for European Integration,” Economic Systems, Vol. 34, No. 1, 2010, pp. 38-54. http://dx.doi.org/10.1016/j.ecosys.2010.01.002

[2] P. De Grauwe, "The Financial Crisis and the Future of the Eurozone,” Bruges European Economic Policy Briefings, 2010.

http://www.econ.kuleuven.be/ew/academic/intecon/Degra uwe/PDG-Publications_recent.htm

[3] D. Gros, "The Euro Sovereign Crisis: The Difficult Transition to Private Sector Involvement," Intereconomics, Vol. 45, No. 6, 2010, pp. 346-350.

[4] D. Lachman, "Europe Fiddles as Its Periphery Burns," Intereconomics, Vol. 45, No. 6, 2010, pp. 353-356.

[5] M. Kumar and A. Persaud, "Pure Contagion and Investor's Shifting Risk Appetite: Analytical Issues and Empirical Evidence,” International Finance, Vol. 5, No. 3, 2002, pp. 401-436.

http://dx.doi.org/10.1111/1468-2362.00102

[6] M. Dungey, R. Fry, B. González-Hermosillo and V. Martin, "Characterizing Global Risk Aversion for Emerging Markets During Financial Crises,” IMF Working Paper 03/251, 2003.

http://www.imf.org/external/pubs/ft/wp/2003/wp03251.p df

[7] V. Coudert and M. Gex, "Does Risk Aversion Drive Financial Crises? Testing the Predictive Power of Empirical Indicators,” Journal of Empirical Finance, Vol. 15, No. 2, 2008, pp. 167-184. http://dx.doi.org/10.1016/j.jempfin.2007.06.001

[8] V. Coudert and M. Gex, "Contagion Inside the Credit Default Swaps Market: The Case of the GM and Ford Crisis in 2005," Journal of International Financial Markets Institutions and Money, Vol. 20, No. 2, 2010, pp. 109-134. http://dx.doi.org/10.1016/j.intfin.2010.01.001

[9] P. Jorion and G. Zhang, "Good and Bad Credit Contagion: Evidence from Credit Default Swaps," Journal of Financial Economics, Vol. 84, No. 3, 2007, pp. 860-883. http://dx.doi.org/10.1016/j.jfineco.2006.06.001

[10] F. Guo, C. R. Chen and Y. S. Huang, "Markets Contagion during Financial Crisis: A Regime-Switching Approach," International Review of Economics \& Finance, Vol. 20, No. 1, 2011, pp. 95-109.

http://dx.doi.org/10.1016/j.iref.2010.07.009

[11] M. Dungey, R. Fry, B. González-Hermosillo and V. Martin, "Contagion in International Bond Markets during the Russian and the LTCM Crises," Journal of Financial Stability, Vol. 2, No. 1, 2006, pp. 1-27. http://dx.doi.org/10.1016/j.jfs.2005.01.001

[12] I. Bunda, A. J. Hamann and S. Lall, "Correlations in Emerging Market Bonds: The Role of Local and Global Factors,” Emerging Markets Review, Vol. 10, No. 2, 2009, pp. 67-96. http://dx.doi.org/10.1016/j.ememar.2009.02.003
[13] T. Gravelle, M. Kichian and J. Morley, "Detecting Shift-Contagion in Currency and Bond Markets,” Journal of International Economics, Vol. 68, No. 2, 2006, pp. 409423. http://dx.doi.org/10.1016/j.jinteco.2005.07.005

[14] D. Egloff, M. Leippold and P. Vanini, “A Simple Model of Credit Contagion," Journal of Banking and Finance, Vol. 31, No. 8, 2007, pp. 2475-2492. http://dx.doi.org/10.1016/j.jbankfin.2006.10.023

[15] F. A. Longstaff, "The Subprime Credit Crisis and Contagion in Financial Markets," Journal of Financial Economics, Vol. 97, No. 3, 2010, pp. 436-450. http://dx.doi.org/10.1016/j.jfineco.2010.01.002

[16] C. Brune and P. Liu, "The Contagion Effect of Default Risk Insurer Downgrades: The Impact on Insured $\mathrm{Mu}-$ nicipal Bonds,” Journal of Economics and Business, Vol. 63, No. 5, 2011, pp. 492-502. http://dx.doi.org/10.1016/j.jeconbus.2010.11.003

[17] M. H. Pesaran and A. Pick, "Econometric Issues in the Analysis of Contagion,” Journal of Economic Dynamics and Control, Vol. 31, No. 4, 2007, pp. 1245-1277. http://dx.doi.org/10.1016/j.jedc.2006.03.008

[18] J. Lee and M. C. Strazicich, "Minimum Lagrange Multiplier Unit Root Test with Two Structural Breaks," Review of Economics and Statistics, Vol. 85, No. 4, 2003, pp. 1082-1089. http://dx.doi.org/10.1162/003465303772815961

[19] J. Lee and M. C. Strazicich, "Minimum LM Unit Root Test with One Structural Break,” Working Paper, Department of Economics, Appalachian State University, 2004. http://econ.appstate.edu/RePEc/pdf/wp0417.pdf

[20] D. A. Dickey and W. A. Fuller, "Distribution of the Estimators for Autoregressive Time Series with a Unit Root," Journal of the American Statistical Association, Vol. 74, No. 366, 1979, pp. 427-431. http://dx.doi.org/10.2307/2286348

[21] J. Lee and M. C. Strazicich, "Minimum LM Unit Root Test with One Structural Break,” Working Paper, Department of Economics, Appalachian State University, 2004. http://econ.appstate.edu/RePEc/pdf/wp0417.pdf

[22] P. Perron, "The Great Crash, the Oil Price Shock, and the Unit Root Hypothesis,” Econometrica, Vol. 57, No. 6, 1989, pp. 1361-1401. http://dx.doi.org/10.2307/1913712

[23] E. Zivot and D. W. K. Andrews, "Further Evidence on the Great Crash, the Oil Price Shock and the Unit Root Hypothesis,” Journal of Business \& Economic Statistics, Vol. 10, No. 3, 1992, pp. 251-270. http://dx.doi.org/10.1080/07350015.1992.10509904

[24] P. Perron, "Further Evidence on Breaking Trend Functions in Macroeconomic Variables," Journal of Econometrics, Vol. 80, No. 2, 1997, pp. 355-385. http://dx.doi.org/10.1016/S0304-4076(97)00049-3

[25] T. J. Vogelsang and P. Perron, “Additional Tests for Unit Root Allowing for a Break in the Trend Function at an Unknown Time," International Economic Review, Vol. 39, No. 4, 1998, pp. 1073-1100. http://dx.doi.org/10.2307/2527353

[26] R. L. Lumsdaine and D. Papell, "Multiple Trend Breaks and the Unit-Root Hypothesis," Review of Economics and 
Statistics, Vol. 79, No. 2, 1997, pp. 212-218. http://dx.doi.org/10.1162/003465397556791

[27] J. Bai and P. Perron, "Estimating and Testing Linear Models with Multiple Structural Changes,” Econometrica, Vol. 66, No. 1, 1998, pp. 47-78. http://dx.doi.org/10.2307/2998540

[28] J. Wang and E. Zivot, “A Bayesian Time Series Model of Multiple Structural Changes in Level, Trend, and Variance,” Journal of Business \& Economic Statistics, Vol. 18, No. 3, 2000, pp. 374-386. http://dx.doi.org/10.1080/07350015.2000.10524878

[29] J. Bai and P. Perron, "Computation and Analysis of MultipleStructural Change Models,” Journal of Applied Econometrics, Vol. 18, No. 1, 2003, pp. 1-22. http://dx.doi.org/10.1002/jae.659

[30] T. CogleyandT. J. Sargent, "Drifts and Volatilities: Monetary Policies and Outcomes in the Post WWII US," Review of Economic Dynamics, Vol. 8, No. 2, 2005, pp. 262-302. http://dx.doi.org/10.1016/j.red.2004.10.009

[31] T. Bollerslev, "Generalized Autoregressive Conditional Heteroscedasticity,” Journal of Econometrics, Vol. 31, No. 3, 1986, pp. 307-327. http://dx.doi.org/10.1016/0304-4076(86)90063-1

[32] C. Gouriéroux and A. Monfort, "Simulation-Based Econometric Methods,” 1st Edition, Oxford University Press, New York, 1996.

[33] R. Liesenfeld and J.-F. Richard, "Univariate and Multivariate Stochastic Volatility Models: Estimation and Diagnostics," Journal of Empirical Finance, Vol. 10, No. 4, 2003, pp. 505-531.

http://dx.doi.org/10.1016/S0927-5398(02)00072-5

[34] L. Bauwens and N. Hautsch, "Stochastic Conditional Intensity Processes," Journal of Financial Econometrics, Vol. 4, No. 3, 2006, pp. 450-493. http://dx.doi.org/10.1093/jjfinec/nbj013

[35] S. Blazsek and A. Escribano, "Knowledge Spillovers in U.S. Patents: A Dynamic Patent Intensity Model with Secret Common Innovation Factors," Journal of Econometrics, Vol. 159, No. 1, 2010, pp. 14-32. http://dx.doi.org/10.1016/j.jeconom.2010.04.004

[36] G. Ljung and G. Box, "On a Measure of Lack of Fit in Time-Series Models,” Biometrika, Vol. 65, No. 2, 1978, pp. 297-303. http://dx.doi.org/10.1093/biomet/65.2.297 


\section{Appendix A}

We write the specification to be estimated as follows:

$$
\begin{gathered}
y_{i t}=\left(1+\phi_{1 i}\right) y_{i t-1}+\phi_{2 i} y_{i t-1}^{2}+\psi_{i} D_{i t}\left(\frac{\sum_{j=1, j \neq i}^{N} I_{j t}}{N-1}\right)+u_{i t} \\
u_{i t}=\gamma_{i} D_{i t} l_{t}^{*}+\sigma_{i} \varepsilon_{i t}, \quad \varepsilon_{i t} \sim N(0,1) \text { i.i.d. } \\
l_{t}^{*}=\mu^{*} l_{t-1}^{*}+\eta_{t}, \quad \eta_{t} \sim N(0,1) \text { i.i.d. }
\end{gathered}
$$

For $i=1, \cdots, N$ and $t=1, \cdots, T$. We introduce the following notation related to the observable and latent variables:

$$
\begin{aligned}
Y_{i t} & =\left(y_{i 1}, \cdots, y_{i t}\right), \\
Y_{t} & =\left(y_{1 t}, \cdots, y_{N t}\right), \\
\tilde{D}_{i t} & =\left(D_{i 1}, \cdots, D_{i t}\right), \\
\tilde{D}_{t} & =\left(\tilde{D}_{1 t}, \cdots, \tilde{D}_{N t}\right), \\
\tilde{I}_{i t} & =\left(I_{i 1}, \cdots, I_{i t}\right), \\
\tilde{I}_{t} & =\left(\tilde{I}_{1 t}, \cdots, \tilde{I}_{N t}\right)
\end{aligned}
$$

and $L_{t}^{*}=\left(l_{1}^{*}, \cdots, l_{t}^{*}\right)$. The density of $y_{i t}$ conditional on $\left(\tilde{D}_{t}, \tilde{I}_{t}, Y_{i t-1}, l_{t}^{*}\right)$ is

$$
f\left(y_{i t} \mid \tilde{D}_{t}, \tilde{I}_{t}, Y_{i t-1}, l_{t}^{*}\right)=\frac{1}{\sqrt{2 \pi \sigma_{i}^{2}}} \exp \left[-\frac{\left(y_{i t}-\tilde{\mu}_{i t}\right)^{2}}{2 \sigma_{i}^{2}}\right],
$$

where the conditional mean of $y_{i t}$ is

$$
\tilde{\mu}_{i t}=\left(1+\phi_{1 i}\right) y_{i t-1}+\phi_{2 i} y_{i t-1}^{2}+\psi_{i} D_{i t}\left(\frac{\sum_{j=1, j \neq i}^{N} I_{j t}}{N-1}\right)+\gamma_{i} D_{i t} l_{t}^{*} \text {. }
$$

The density of the latent factor, $l_{t}^{*}$ conditional on $l_{t-1}^{*}$ is

$$
f^{*}\left(l_{t}^{*} \mid l_{t-1}^{*}\right)=\frac{1}{\sqrt{2 \pi}} \exp \left[-\frac{\left(l_{t}^{*}-\mu^{*} l_{t-1}^{*}\right)^{2}}{2}\right] .
$$

Since the $L_{T}^{*}$ is not observed, we integrate out all latent variables from the likelihood function with respect to the assumed normal distribution, to get the marginal density of $Y_{T}$. The integrated likelihood function is the following $T$-dimensional integral:

$$
\begin{aligned}
& \mathcal{L}\left(Y_{T}, \theta\right) \\
& =\int_{\mathbb{R}^{T}} \prod_{i=1}^{N} \prod_{t=1}^{T} f\left(y_{i t} \mid \tilde{D}_{t}, \tilde{I}_{t}, Y_{i t-1}, l_{t}^{*}\right) f^{*}\left(l_{t}^{*} \mid l_{t-1}^{*}\right) d L_{T}^{*}
\end{aligned}
$$

We can rewrite the likelihood of $Y_{T}$ by using a more compact notation as follows:

$$
\begin{aligned}
\mathcal{L}\left(Y_{T}, \theta\right) & =\int_{\mathbb{R}^{T}} g\left(Y_{T}, L_{T}^{*} \mid \tilde{D}_{T}, \tilde{I}_{T}, \theta\right) d L_{T}^{*} \\
= & \int_{\mathbb{R}^{T}} \prod_{i=1}^{N} \prod_{t=1}^{T} g\left(y_{i t}, l_{t}^{*} \mid \tilde{D}_{t}, \tilde{I}_{t}, Y_{i t-1}, L_{t-1}^{*}, \theta_{t}\right) d L_{T}^{*}
\end{aligned} .
$$

where $g$ is the joint density of debt to GDP and the latent factor. For given parameter values, we evaluate the $T$-dimensional integral numerically in $\mathcal{L}$ by Monte Carlo (MC) simulation method, using the EIS technique ([19]). The EIS procedure is nested into a typical likelihood function maximization procedure. To maintain the stability of this procedure, the same set of i.i.d. $N(0,1)$ random numbers (i.e., common random numbers) is used for every set of parameters to estimate the value of the integrated likelihood function (see [19]). The EIS methodology consists of the following elements. First, an auxiliary sampler, $m$ is introduced and it is included in the likelihood function as follows:

$$
\begin{aligned}
\mathcal{L}\left(Y_{T}, \theta\right)= & \int_{\mathbb{R}^{T}} \prod_{i=1}^{N} \prod_{t=1}^{T} \frac{g\left(y_{i t}, l_{t}^{*} \mid \tilde{D}_{t}, \tilde{I}_{t}, Y_{i t-1}, L_{t-1}^{*}, \theta_{t}\right)}{m\left(l_{t}^{*} \mid L_{t-1}^{*}, \theta_{t}^{*}\right)}, \\
& \times m\left(l_{t}^{*} \mid L_{t-1}^{*}, \theta_{t}^{*}\right) d L_{T}^{*}
\end{aligned}
$$

where $\theta_{t}^{*}$ denotes the parameters of the auxiliary sampler in period $t$. Then, the importance MC estimate of $\mathcal{L}\left(Y_{T}, \theta\right)$ for given $\theta_{t}^{*}$ is computed as

$$
\begin{aligned}
& \hat{L}_{R}\left(Y_{T}, \theta, \theta^{*}\right) \\
& =\frac{1}{R} \sum_{r=1}^{R} \prod_{i=1}^{N} \prod_{t=1}^{T} \frac{g\left(y_{i t}, l_{t r}^{*} \mid \tilde{D}_{t}, \tilde{I}_{t}, Y_{i t-1}, L_{t-1 r}^{*}, \theta_{t}\right)}{m\left(l_{t r}^{*} \mid L_{t-1 r}^{*}, \theta_{t}^{*}\right)}
\end{aligned}
$$

where $\theta^{*}$ is the vector of parameters of the auxiliary sampler including all $\theta_{t}^{*}$ with $t=1, \cdots, T$, and $\left\{l_{t r}^{*}: t=1, \cdots, T\right\}$ denotes the $r$-th trajectory of i.i.d. draws from $\left\{m\left(l_{t}^{*} \mid L_{t-1}^{*}, \theta_{t}^{*}\right): t=1, \cdots, T\right\}$ and $r=1, \cdots, R$. Regarding the auxiliary sampler, the following two questions are to be answered:

1) How to simulate from $m\left(l_{t}^{*} \mid L_{t-1}^{*}, \theta_{t}^{*}\right)$ ? [19] suggest defining the auxiliary sampler, $m$ with its associated density kernel, $k$, defined as

$$
k\left(L_{t}^{*}, \theta_{t}^{*}\right)=m\left(l_{t}^{*} \mid L_{t-1}^{*}, \theta_{t}^{*}\right) \chi\left(L_{t-1}^{*}, \theta_{t}^{*}\right),
$$

where

$$
\chi\left(L_{t-1}^{*}, \theta_{t}^{*}\right)=\int_{\mathbb{R}} k\left(L_{t}^{*}, \theta_{t}^{*}\right) d l_{t}^{*}
$$

denotes the integrating constant associated to $k$ in period $t$. [19] suggest choosing $k$ as a kernel of the normal distribution, i.e. the exponential of a second- order polynomial. Following [34], $f^{*}$ is included into the auxiliary sampler, $m$. Therefore, the normal density kernel in period $t$ has the following form: 


$$
k\left(L_{t}^{*}, \theta_{t}^{*}\right)=\exp \left[\theta_{1 t_{t}^{*}}^{*}+\theta_{2 t}^{*}\left(l_{t}^{*}\right)^{2}\right] \times \exp \left[-\frac{\left(l_{t}^{*}-\mu^{*} l_{t-1}^{*}\right)^{2}}{2}\right],
$$

where the vector of parameters $\theta_{t}^{*}=\left(\theta_{1 t}^{*}, \theta_{2 t}^{*}\right)$ determines the conditional mean and the conditional variance of the auxiliary sampler, $m$ in period $t$. From Equation (13), we can derive that the conditional mean, $\mu_{t}$ and conditional variance, $\pi_{t}^{2}$ of $m$ in period $t$ are

$$
\mu_{t}=\pi_{t}^{2}\left(\theta_{1 t}^{*}+\mu^{*} l_{t-1}^{*}\right)
$$

and

$$
\pi_{t}^{2}=\frac{1}{1-2 \theta_{2 t}^{*}},
$$

respectively; see also [34]. Therefore, for given parameters of the auxiliary sampler, a trajectory of $l_{t}^{*}$ can be generated from the following AR (1) process:

$$
l_{t}^{*}=\mu_{t}+\pi_{t} \eta_{t},
$$

where $\eta_{t} \sim N(0,1)$ are i.i.d. common random numbers.

2) How to choose the $\theta_{t}^{*}$ parameters of $m$ ? The EIS methodology relies on the optimal choice of parameters of the auxiliary samplers in the sense that for a given $m$, the variance of $\hat{L}_{R}\left(Y_{T}, \theta, \theta^{*}\right)$ is minimized, i.e.,

$$
\theta^{*}\left(Y_{T}, \theta\right)=\arg \min _{\theta^{*}} \operatorname{Var}\left[\hat{L}_{R}\left(Y_{T}, \theta, \theta^{*}\right)\right] .
$$

From Equation (10), one can guess that this variance is "small" when $m$ provides a "good fit" to $g$ in each period $t$. Equation (11) shows that $m$ may provide a "good fit" to $g$ if

$$
\begin{aligned}
& \ln g\left(y_{i t}, l_{t}^{*} \mid \tilde{D}_{t}, \tilde{I}_{t}, Y_{i t-1}, L_{t-1}^{*}, \theta_{t}\right)+\ln \chi\left(L_{t-1}^{*}, \theta_{t}^{*}\right) \\
& \cong \ln k\left(L_{t}^{*}, \theta_{t}^{*}\right)
\end{aligned}
$$

for each period $t=T, \cdots, 1$. Using the fact that $\ln k$ is a second-order polynomial of $l_{t}^{*}$ for a normal distribution, [19] show that the MC variance minimization problem stated in Equation (17) can be reduced to the following recursive sequence of $T$ ordinary least squares (OLS) problems:

$$
\begin{aligned}
& \operatorname{ng}\left(y_{i t},,_{t r}^{*} \mid \tilde{D}_{t}, \tilde{I}_{t}, Y_{i t-1}, L_{t-1 r}^{*}, \theta_{t}\right)+\ln \chi\left(L_{t r}^{*}, \theta_{t+1}^{*}\right) \\
& =\theta_{0 t}^{*}+\theta_{1 t}^{*} l_{t r}^{*}+\theta_{2 t}^{*}\left(l_{t r}^{*}\right)^{2}+u_{t r}
\end{aligned}
$$

For $t=T, \cdots, 1 \quad$ and $\quad r=1, \cdots, R . \quad \chi\left(L_{T r}^{*}, \theta_{T+1}^{*}\right)=1$ and $\hat{\theta}_{t+1}^{*}$ is the OLS estimate of $\theta_{t+1}^{*}$. Thus, for each period $t$, one has to compute the OLS estimate of the parameters of the auxiliary sampler, $m$. The regressions have a recursive structure because the $\hat{\theta}_{t+1}^{*}$ estimates are used to compute the integrating constant for the next, $t$ th OLS regression. Thus, the regressions are run backwards, i.e. from $T$ to 1 . The sample size of each re- gression is equal to the number of trajectories drawn, $R$. One of the advantages of the EIS algorithm is that these auxiliary regressions are typically run with relatively low sample sizes. In this article, the number of trajectories simulated for the latent variables is $R=50$.

In summary, the EIS technique consists of the following steps:

a) Draw $R$ trajectories $\left\{l_{t r}^{*}\right\}_{t=1}^{T}$ from the natural sampler, $N\left(\mu^{*} l_{t-1 r}^{*}, 1\right)$.

b) For each $t$ (from $T$ to 1 ), estimate the regression in Equation (19).

c) Given the OLS estimates of $\theta^{*}$ obtained in 2), draw $R$ trajectories $\left\{l_{t r}^{*}\right\}_{t=1}^{T}$ from the auxiliary samplers, $\left\{m\left(l_{t}^{*} \mid L_{t-1}^{*}, \theta_{t}^{*}\right): t=1, \cdots, T\right\}$. Iterate 2) and 3) five times ([19]).

d) From Equation (11), express $m$ for each period as:

$$
m\left(l_{t}^{*} \mid L_{t-1}^{*}, \theta_{t}^{*}\right)=\frac{k\left(L_{t}^{*}, \theta_{t}^{*}\right)}{\chi\left(L_{t-1}^{*}, \theta_{t}^{*}\right)} .
$$

It can be deduced from Equations (12) and (13) that

$$
\chi\left(L_{t-1}^{*}, \theta_{t}^{*}\right)=\sqrt{2 \pi \pi_{t}^{2}} \times \exp \left[-\frac{\left(\mu^{*}\right)^{2}\left(l_{t-1}^{*}\right)^{2}}{2}+\frac{\mu_{t}^{2}}{2 \pi_{t}^{2}}\right] .
$$

Therefore, we can compute the importance MC estimate of $\hat{L}_{R}$ of (11) by Equations (13), (20) and (21).

\section{Appendix B}

The value of the latent factor is approximated by estimating the expectation of $l_{t}^{*}$ conditional on the past observable information set, i.e., $\tilde{l}_{t}^{*}=E\left[l_{t}^{*} \mid \tilde{D}_{t-1}, \tilde{I}_{t-1}, Y_{t-1}\right]$; see [34]. This conditional expectation can be computed as

$$
E\left[l_{t}^{*} \mid \tilde{D}_{t-1}, \tilde{I}_{t-1}, Y_{t-1}\right]=\int_{\mathbb{R}} l_{t}^{*} h\left(l_{t}^{*} \mid \tilde{D}_{t-1}, \tilde{I}_{t-1}, Y_{t-1}\right) d l_{t}^{*},
$$

where $h$ denotes the conditional density of $l_{t}^{*}$. We can compute $h$ as follows:

$$
\begin{aligned}
& h\left(l_{t}^{*} \mid \tilde{D}_{t-1}, \tilde{I}_{t-1}, Y_{t-1}\right)=\frac{g\left(Y_{t-1}, l_{t}^{*} \mid \tilde{D}_{t-1}, \tilde{I}_{t-1}\right)}{f\left(Y_{t-1} \mid \tilde{D}_{t-1}, \tilde{I}_{t-1}\right)} \\
& =\frac{\int_{\mathbb{R}^{t-1}} f^{*}\left(l_{t}^{*} \mid l_{t-1}^{*}\right) g\left(Y_{t-1}, L_{t-1}^{*} \mid \tilde{D}_{t-1}, \tilde{I}_{t-1}\right) d L_{t-1}^{*}}{\int_{\mathbb{R}^{t-1}} g\left(Y_{t-1}, L_{t-1}^{*} \mid \tilde{D}_{t-1}, \tilde{I}_{t-1}\right) d L_{t-1}^{*}}
\end{aligned}
$$

Substituting Equation (23) into (22), and using the fact that the denominator in (23) is not a function of $l_{t}^{*}$, we obtain that

$$
\begin{aligned}
& E\left[l_{t}^{*} \mid \tilde{D}_{t-1}, \tilde{I}_{t-1}, Y_{t-1}\right] \\
& =\frac{\int_{\mathbb{R}^{t}} l_{t}^{*} f^{*}\left(l_{t}^{*} \mid l_{t-1}^{*}\right) g\left(Y_{t-1}, L_{t-1}^{*} \mid \tilde{D}_{t-1}, \tilde{I}_{t-1}\right) d L_{t}^{*},}{\int_{\mathbb{R}^{t-1}} g\left(Y_{t-1}, L_{t-1}^{*} \mid \tilde{D}_{t-1}, \tilde{I}_{t-1}\right) d L_{t-1}^{*}}
\end{aligned}
$$

where the joint density, $g$ is given by 


$$
\begin{aligned}
& g\left(Y_{t-1}, L_{t-1}^{*} \mid \tilde{D}_{t-1}, \tilde{I}_{t-1}\right) \\
& =\prod_{i=1}^{N} \prod_{s=1}^{t-1} f\left(y_{i s} \mid \tilde{D}_{s}, \tilde{I}_{s}, Y_{i s-1}, l_{s}^{*}\right) f^{*}\left(l_{s}^{*} \mid l_{s-1}^{*}\right)
\end{aligned}
$$

The high-dimensional integrals in Equation (24) are (25) estimated by the EIS technique. 